\title{
OFFERING AUTHENTIC LEARNING ACTIVITIES IN THE CONTEXT OF OPEN RESOURCES AND REAL-WORLD GOALS: A STUDY OF SELF- MOTIVATED ONLINE MUSIC LEARNING
}

\author{
Catherine Schmidt-Jones[caschmidtjones@gmail.com], \\ University of Illinois at Urbana-Champaign, United States of America
}

\begin{abstract}
Many users of online open education resources (OERs) are learners seeking insights into problems encountered as they pursue their everyday interests and activities. As well as benefitting from intrinsic motivation, such authentic learning activity provides context that helps the learner absorb and integrate the meaning of the knowledge. The purpose of this study was to explore barriers that prevent some online learners from using OERs in this way. Participants had experienced difficulties using music theory OERs to pursue personal music-making goals. Provided with online tutoring through an action research methodology, they appeared to benefit particularly from five aspects of active guidance: additional motivation, connections between generalized knowledge and personal experience, relevant learning activities, focus of attention, and goal-oriented feedback. In an environment rich in open content, providing these supports, in activities oriented towards learners' goals, may be a particularly valuable use of teaching time.
\end{abstract}

Keywords: open education resources, authentic learning activity, online music learning, inquirybased learning, action research

\section{Introduction}

I first heard of open education resources (OERs) in 2002, from engineering professors who were collaborating at Connexions (currently OpenStax, https://cnx.org) to create modular materials that could easily be shared, reconfigured and reused as needed in various courses. As a music teacher, I had long felt that standard textbook-based approaches to music theory failed to demonstrate the practical usefulness of the concepts. Instead, I introduced concepts as they became relevant to a student's musical practices and goals, but there were no texts available to support that approach. Easily accessible modular materials seemed like an ideal solution, one that I suspected other teachers might also appreciate. Online educational materials were scarce at the time, and Connexions accepted materials from any educator willing to share, so I published several modules on crucial music theory concepts. Encouraged by high visit numbers, high placements in Google search results, and enthusiastic emails from readers, I published more modules, organized them into online courses, and became interested in open education as a research area.

I originally assumed my OERs, like the engineering materials, would primarily be used to create customized curricula. However, in a voluntary survey of users (Schmidt-Jones, 2012), nearly all respondents related their use of the materials to pursuit of their own goals, rather than to any curriculum. This finding was supported by concurrent analytics evidence suggesting that most users were looking up specific concepts, rather than following the online courses. Respondents generally rated the materials as very helpful in this context. Some volunteered positive comments about easy readability that echoed the enthusiastic emails. In spite of this, some respondents with minimal formal music education were clearly struggling to make use of the OERs. 
Other research (e.g. Carson, 2006; 2009; Rosell-Aguilar, 2013) corroborates the finding that a large portion of OER use is motivated by personal goals, rather than course or certification goals. OER support of self-motivated learning enables individuals to follow their own passions (Brown \& Adler, 2008) and to seamlessly connect in- and out-of-school learning (Fletcher, Schaffhauser, \& Levin, 2012). In a fast-paced world that rewards lifelong learning, this may create a "digital divide" disadvantage for individuals who have difficulty using OERs independently.

Kop, Fournier, and Mak (2011) distilled the quest to widen access to lifelong online learning into two basic questions: "What would be the important factors in the design of a learning environment to support learner self-direction on online networks, and what should be the place and role of the educator?" (p.76). I undertook the current study as an OER provider seeking answers to the first question; I hoped the findings would help me design materials that were more accessible to independent learners. However, the methodology involved working closely with self-motivated online music learners, in order to better understand their needs and difficulties. These generated findings that are relevant to the second question and have affected the direction of my OER research and development.

Some approaches to using technology in education are designed to replace interaction between teacher and learner, which may account for some learner dissatisfaction with them (Godin, 2012). In my view, OERs instead support lifelong learning through the type of seamless movement between teacher-facilitated and independent inquiry envisioned by Fletcher, Schaffhauser, and Levin (2012). The findings of this study point to five types of supports that OER users may particularly value and seek from teachers: additional motivation, connections between generalized knowledge and personal experience, relevant learning activities, focus of attention, and goaloriented feedback. Providing these supports may also improve students' subsequent ability to learn independently. Study findings that relate to active teaching are the focus of this paper; please see Schmidt-Jones (2016a) for discussions of the findings regarding the design and content of OERs.

\section{Literature Review}

\section{Informal and formal music learning}

A constructivist perspective holds that individuals construct their own meaningful and functional understandings, through social activities that reveal how others make use of knowledge (Vygotsky, 1978). Such knowledge construction typically occurs informally, in the course of everyday practices undertaken by communities working together to achieve their goals (Wenger, 1998). For example, most music learning takes place informally, as people create, practice, and enjoy music together (Green, 2002; Lilliestam, 1996). Learning in communities of practice may also involve apprenticeships that pass on specific skills and roles valued by the community (Rogoff, 1990). For example, in most folk music traditions, novice instrumentalists learn primarily through playing alongside more experienced performers (Nettl, 1985).

Much of the knowledge gained informally in communities of practice and through apprenticeships is tacit. Consciously-learned, concept-rich knowledge is more typically taught in formal education settings. Conceptual knowledge gives individuals more control over their own mental activity (Vygotsky, 1978); music theory, for example, affords more purposeful choices in creative activities such as composing. Unfortunately, traditional education methods often abstract the concepts too completely from their socially-motivated, goal-oriented contexts. As Brown, Collins, and Duguid (1989) have pointed out, this can cause the knowledge to become so strongly indexed to classroom activities that it is not triggered by the real-world problems for which it is 
meant to be used: "The activity in which knowledge is developed and deployed. ... is an integral part of what is learned" (p.32).

Standard music education provides examples: Theory courses typically present concepts in the context of classical music and harmony-writing exercises, ignoring the musical genres and activities that are more in line with students' extracurricular interests (Bresler, 1993). Formal instrumental instruction does not reproduce key aspects of the apprenticeship model (Green, 2002). New music technologies are too often used for formulaic exercises, rather than the types of creative activities for which they were designed (Crawford, 2014).

Learners may react to this abstraction by assuming that formal knowledge lacks real-world value and relevance. Many music traditions explicitly reject formal music education, with informal learning described as "more authentic" by both learners (Hargreaves \& Marshall, 2003) and professionals (Lilliestam, 1996). Green (2002) noted that "music education has had relatively little to do with the development of the majority of those musicians who have produced the vast proportion of the music which the global population listens to, dances to, identifies with, and enjoys" (p.5). Woody and Lehmann (2010) found that formally trained musicians had fewer and less efficient music-problem-solving strategies than those with "vernacular" experience.

\section{Authentic music theory learning}

Yet, because music theory does enable intrinsically motivating, creative activities, some informally educated musicians become interested in learning it (Green, 2002). A few manage to take theory courses, but others struggle to do so, or are unwilling to pursue courses that are not explicitly tied to their interests (Schmidt-Jones, 2012). Authentic learning activities involve solving problems that are complex, open-ended, and oriented towards a goal that makes sense to the learner. Music offers a myriad of opportunities for such activities (Crawford, 2014). For example, authentic music theory learning involves applying the concepts to problems that learners encounter when they try to create music that interests them, using their chosen instruments. This situates the learning, and the knowledge acquired, in contexts that matter to the learners, simultaneously creating and revealing its real-world value.

Modern music-making practices have rendered apprentice-style learning much less available (Green, 2002). Many musicians engage instead in self-directed learning, in which they consciously plan, direct, and evaluate their own knowledge acquisition. Self-directed learning "is not exclusively an informal learning process. It can and does occur in formal educational settings, usually under the guidance of an expert teacher and/or in concert with group learning activities" (Peters, Taylor, \& Doi, 2009; p.25). Such guidance allows learners to work within the zone of proximal development, the level at which they are not yet able to solve problems independently but can do so with assistance (Vygotsky, 1978).

Inquiry based learning provides one model for self-directed, authentic learning activities. Inquiry is envisioned as an open-ended spiral, consisting of cycles of problem-posing, research, creative response, and reflection that lead naturally to the next problem-posing cycle (Wells, 2001). The learner retains substantial control over both the means (such as the materials and procedures used) and the ends (such as the work created and the educational goal) of the activity, even when it is facilitated by an instructor.

Authentic inquiry can be supported by technological artefacts that are intentionally designed for it (Boitshwarelo, 2011). Crawford (2014) lists several ways that technology can support authentic music learning, including giving students access to real-world sources and empowering them to take ownership of the learning process. The open-access, modular approach taken by OERs 
seems well suited to provide these affordances to self-directed learners, many of whom can use well-designed resources independently. However, the findings of this study suggest that, at any level of expertise, learners may need or want active guidance within the authentic contexts supported by open content.

\section{The research perspective: Action research and activity theory}

Users of music OERs may lack formal background, either by choice or due to lack of opportunity (Schmidt-Jones, 2012). This creates barriers to learning that are not well researched; self-directed online learning is intrinsically more difficult to study than formal online learning (Harley, 2008). Action research (AR) provides a pragmatic methodology for engaging selfdirected online learners. In AR, the researcher takes action with others, with simultaneous goals of improving a specific real-world practice while also contributing to the academic discourse on such practices (Herr \& Anderson, 2005; Reason \& Bradbury, 2006). Participatory action research in particular focuses on working with other stakeholders in the practice, treating them as knowledgeable co-researchers whose perspectives and understandings raise important issues and provide key insights (Heron \& Reason, 2006). AR and self-directed learning involve similar processes, creating a compatibility of perspective that can strengthen a study (Peters, Taylor, \& Doi, 2009).

In order to be responsive to participant perspectives, AR studies are open to unexpected changes in direction, including choosing the theoretical framework for data analysis after emerging issues become clear. "Activity theory is a powerful and clarifying descriptive tool rather than a strongly predictive theory" (Nardi, 1996; p.7), providing a sociocultural framework that can be applied in the analysis phase of a study. First developed by Vygotsky's student, Leontiev, activity theory posits that activity and knowledge are not separable. Attempts to characterize knowledge in terms of contextless individuals or objects are considered misleading; studying activity is considered the best approach to understanding learning. The basic unit of analysis is an activity in its entirety, including the people involved, their interactions, the physical and conceptual tools used, and the immediate object and underlying goal of the activity (Leontiev, 1978). Welch (2007) and Burnard (2007) have both recommended activity theory as a holistic approach that can take into account the multifaceted nature of music learning, including its creative and technological aspects.

\section{Methodology}

Action research is often described as an inquiry "spiral of iterative cycles of plan-act-observereflect" (Herr \& Anderson, 2005; p.47). Boitshwarelo (2011) recommends iterative development of technological artefacts that are meant to support authentic learning, at each stage seeking "to understand the learning ecology of the authentic contexts where the designed objects are used" (p.165). This study represented one cycle of an action-research project aimed at developing more accessible OERs. OER creation is a labour-intensive action best undertaken after a fruitful round of observation, reflection, and planning. The 2012 survey of users did not provide sufficient insights, in part because it lacked the in-depth, sustained interaction that helps a teacher understand the specific needs, backgrounds, and perspectives of learners. The action undertaken in the current study was therefore to work closely with participants, guiding their inquiries in order to develop a deeper understanding of them. Reflection on the findings could then inform my further actions as an OER researcher and developer.

To date, there have been few online action research studies, but the methodology is purposefully flexible; research methods and techniques are chosen to reflect the specific situation under study. In the area of education, AR often takes the form of an inquiry conducted by a teacher who facilitates the inquiries of student-participants with the goal of improving her own practice 
(Wells, 2001). This approach resonates with the goals of this study, as well as with the learnercentric ethic of open education (Cape Town Open Education Declaration, 2007). By offering visitors to my OERs additional help in reaching their own goals, I hoped to attract study participants who experienced difficulties using the OERs independently. As co-researchers and learner-stakeholders in the materials, their perspectives might reveal useful insights regarding the barriers they had encountered.

\section{Study sites and participants}

The call for participants was linked from my 50 most popular OER modules, each of which used a mix of text, illustrations, and audio files to introduce a concept in music theory, notation, or acoustics. The only registration requirement was that the participant be between the ages of 18 and 65. As is typical of online studies, the registration rate was low and the dropout rate high. Google analytics indicated that the modules together were averaging about 2690 visits per day, but only 60 volunteers responded during the five months that the link was available. Eleven undertook lengthy inquiries within the study; the rest dropped out without attempting to make progress. My analysis focused on understanding the long-term inquiries, but I also compared the known characteristics of long-term participants as a group to study dropouts as a group. Participants' backgrounds, goals, and progress varied so widely that is not possible to describe a "representative" inquiry. Instead, I have chosen five participants to illustrate the variety and provide a sense of the inquiry process.

Sonia was a 54-year-old living in the United States who had taken piano lessons periodically since childhood, including jazz piano. She finished two inquiries within this study. In the first, she asked for help keeping up with an "Intro to Improvisation" massive open online course (MOOC) that she was taking. We used her MOOC coursework, which consisted of self-recorded improvisations, to discuss and work on improvisation skills and the relevant concepts. In the second inquiry, she composed in a jazz style. Resources for Sonia's inquiries included hard-copy books that she owned, as well as the MOOC materials and forum. Her improvisations, selfreports, compositions, and use of terminology all showed evidence of progress.

Jeff was a 22-year-old living in South Africa. Although lacking in formal music education, he was a competent digital audio workstation (DAW) composer. Jeff's goal was to create melodies and harmonies similar to those in a popular anime music style. Because he was unfamiliar with common notation, we used his DAW's "piano roll view" to illustrate our discussions. Most of Jeff's activities involved choosing a small portion of a piece he admired, such as a melody or chord progression, and creating a DAW version of it by ear. We then used standard music-theory concepts to discuss the fragment, and he followed up with short original compositions demonstrating his understanding of the concepts. Our discussions served as the main resource for his inquiry, although Jeff also consulted some books and open online materials. His compositions demonstrated an increasing ability to purposefully use concepts such as power chord and minor mode to create the desired musical style.

James was a 44-year-old living in Canada who had played guitar as a hobby for over fifteen years. He expressed his inquiry goal as "learn harmony, chord progressions, composition" (James, introductory questionnaire). His local materials were typical of what is available: guitar books that lack theory discussions, and a "piano-centric theory book" (James, contact 5). He initially found the breadth of the OERs overwhelming, but within the structure provided by the guided inquiry he volunteered that they were easy to understand. Over the course of a variety of activities that included practice notating named chords, naming chords by ear, creating chord progressions that he liked, and improvising over those progressions, James demonstrated increasing ability and 
confidence in naming and notating specific harmony concepts, as well as recognizing them by ear and using them creatively.

Lee was a 63-year-old living in Singapore who played piano with a group in church services. She had been told that her skills were inadequate in comparison with the other pianists on the roster. She could not instantly transpose music to a different key, nor could she improvise a piano part when provided only with melody and chord symbols. Her inquiry goal was to gain these skills, and the main resources were the music she played in church and our discussions. Most of her inquiry activities involved interpreting chord symbols and creating piano parts based on them. She called this approach "on-the-job-training" and reported that it was much less stressful than trying to follow the generalized rules found in formal materials on transposition and improvisation. However, Lee was one of only two long-term participants who did not appear to progress towards her goal during the study.

Glen was a 31-year-old living in the US. His background included extensive private guitar instruction, university-level theory courses, and experience performing in, and composing for, rock/metal bands. Glen was interested in creating compositions that explored various theory concepts, sound qualities, and instrument techniques. He stated firmly that he was not interested in learning more theory, citing a history of teachers who were interested only in the correctness of theory, rather than in its creative uses. His inquiry activity centred around submitting, discussing, and repeatedly revising several short compositions.

These participants are featured here because each provided a particularly clear example of one of the five aspects of active guidance that appeared to be most useful. To illustrate the breadth of their usefulness, additional examples from these participants round out the discussion of each aspect. To keep the paper to a reasonable length, examples from other participants are not included.

\section{Inquiry Processes}

To protect their privacy, participants were registered under pseudonyms in a closed Moodle course site at my university. Data about them was gathered through the closed site, and the pseudonyms are used in all discussions of them. Participation began with a questionnaire that included questions about musical goals and experience as well as demographics. The next step was to design, with my help, an inquiry that was feasible within the constraints of the study and well aligned with personal goals. Participants were then free to work at their own pace, to contact me for guidance as much or as little as desired, and to leave the study whenever they wished. Study interactions took place in one-on-one discussion forums at the Moodle site. Apart from that site, participants were free to consult any tools, instruments, materials, and people they felt were helpful, including local as well as open online resources. This openness to the goals, processes and resources preferred by the participants was in keeping with standard practices for both action research (Wells, 2001) and adult inquiry (Knowles, 1984) and was aimed at eliciting as much information as possible about how participants had previously approached their goals and how to improve their progress.

\section{Data Sources}

The primary data sources were the texts of the discussion forums, where participants asked questions, expressed concerns and enthusiasms, reported difficulties and progress, discussed and linked to resources, and responded to questions I posed in my role as teacher-researcher. Secondary data sources, which provided triangulation in the form of different perspectives on the issues that emerged in the discussions, included the online resources linked or referenced, 
bespoke materials that I created for some of the inquiries, my researcher's journal, and work submitted by the participants.

\section{Coding and Analysis}

The coding system began with issues that I expected but evolved continuously as the participants' actual issues emerged. When the study site closed, one year after opening, I recoded all data using the final coding system. The issues that emerged fell easily into two thematic categories: the physical and conceptual tools that are used to learn about music, and the teacher-learner interactions involved. However, because the characteristics of the individual inquiries were so varied, it was difficult to disentangle findings regarding these two categories. The holistic approach provided by activity theory provided a way forward, with each inquiry framed as a series of activities with objects and goals that were explicitly agreed in the discussion forums. This allowed the analysis to focus on determining what specifically had changed in a participant's activity when they began to experience progress. Unexpectedly, changes in the immediate object of the activity often proved as crucial as changes in tools or interactions, and all of these appeared to play a role in defining the types of active teaching that benefit self-motivated online learners. (See Schmidt-Jones, 2016b for further discussion of the use of activity theory in this study).

\section{Findings}

The study was driven by the goal of creating OERs that are easier for learners to use independently, with no personal teacher engagement. However, the AR methodology provided teacher engagement, so that participants would have a strong incentive to reveal their needs and perspectives. The results did suggest some intriguing possibilities regarding OER design, but in many cases the change from unsuccessful to successful learning activity was brought about mainly by elements that, at present, can only be provided through personal teacher engagement. The types of assistance provided varied greatly, creating the most complex and difficult-toorganize set of analysis codes. When viewed in terms of changes in activity that triggered progress, useful assistance appeared to fall into five categories:

- additional motivation,

- connections between generalized knowledge and personal experience,

- relevant learning activities,

- focus of attention, and

- goal-oriented feedback.

These categories represent five aspects of my actions as inquiry facilitator, rather than separate actions. For example, the point of many of the learning activities was to create knowledgeexperience connections, and I tried to make my feedback motivational. The aspects themselves are separable, however; relevant learning activities can have purposes other than creating knowledge-experience connections, and feedback can be demotivating.

\section{Additional motivation}

The intrinsic motivation that drives authentic activities is never entirely self-generated, even in independent learners. The assumptions and goals of the relevant community of practice deeply influence how the learner frames personal challenges and their possible solutions (Vygotsky, 1978; Wenger, 1998). In this study, my involvement in the participants' inquiries appeared to increase their immediate motivation in two ways: through implied expectations of timely progress, and through positive interactions regarding their goals and activities. 
Sonia reported difficulty following the discussions of the more experienced students who dominated the MOOC forum; she was reluctant to interrupt with novice-level questions. "Some have left the course because they found it too difficult to navigate on their own. I could have been one of those statistics had I not had your help to get me oriented in the right direction" (Sonia, contact 19). Participation in the MOOC probably contributed to Sonia's progress, but she repeatedly complained that the pace was too fast for her. Unlike OER-supported inquiry, MOOC participation called for linear progress at a standardized pace. Intriguingly, when the MOOC ended, a group of students including Sonia continued to share their improvisations with each other, but at half the pace.

Other study participants seemed to treat their inquiries as an incentive to make faster progress towards their goals. Participation was explicitly self-paced, yet they often volunteered apologies or explanations for lack of progress:

\author{
No progress yet. Sorry. Work hasn't lightened up yet. (Glen) \\ I'm just having way too much fun with this, which can cause me to dwell on certain aspects \\ longer than I perhaps should. (James) \\ Been very busy and got a new computer so haven't had time. (Jeff) \\ Can I do this later in a couple of days time please? (Lee) \\ I took an extended trip out of town and just got back a few days ago. (Sonia)
}

They appeared to have brought to the study an internalized sense of what constituted a reasonable pace, creating an additional motivation to find time for their learning projects when a teacher was involved. Some participants appeared to adopt the closure of the study site as a personal deadline for finishing a project:

When is the last day I can post here? (Glen)

Thanks for ... extending the deadline [for closing the study site]. I am really thrilled to finish this project. (Sonia)

Are you closing your class soon? (Lee)

They also appeared to be motivated by my active interest in their inquiries. For example, participants sometimes responded even to constructive criticism with thanks for my "encouragement". Several asked whether they were supplying enough data for the study; Glen in particular expressed concern that his slow pace might be harming my research. The idea that what they were doing was not only adequate but actually helpful - that their progress was also helping me reach my goals - appeared to be an additional motivation.

As with the implied "reasonable pace", this additional motivation may have been tied to a sense that it was possible to meet expectations. Lee reported negative psychological effects from playing with a group whose expectations she found difficult to meet. Her inquiry may have been less successful in part because she could not frame her goals in terms of progress that she believed she could achieve. 


\section{Connecting formal knowledge and experience}

When education does not help learners link formal knowledge to real-world experiences, they may have trouble making such connections for themselves. When I designed this study, I expected it would attract mainly inexperienced musicians who had difficulty finding OERs that were relevant to their learning goals. Instead, most participants were capable musicians who could easily find relevant information but consistently had trouble making use of it, due to difficulties connecting the generalized concepts to their specific experiences and goals. In fact, this type of difficulty appeared to be the main barrier to independent learning in most cases (Schmidt-Jones, 2016a).

Jeff was seeking knowledge about scales and chords, but he assumed that the scales and chords featured in theory courses were not relevant to the music he liked. As well as focusing on classical music, the courses and texts use common notation, which he could not read, to explain and illustrate concepts. Working in the context of his chosen genre and his DAW screen allowed Jeff to discover that the scales and chords featured in basic theory texts were in fact relevant and useful. His responses consistently indicated eagerness to continue learning in this way: "It makes a lot of sense to me and is EXTREMELY amazing and interesting. ... I don't know much about tonality either. If you could maybe explain it in the ways best and easiest to understand" (Jeff, contact 7).

Sonia's difficulty in creating knowledge-experience connections mainly stemmed from a lack of practice, due to her novice status as a jazz improviser and the fast pace of the MOOC. James' stemmed in part from the fact that his chosen instrument and genres are associated with informal learning practices. Much of my activity within their inquiries involved helping participants connect theory concepts to their experiences and goals. As with Jeff, I did this by using the relevant concepts to discuss their activities, which provided a context that included familiar genres, instruments, and visual representations of music, and by suggesting additional authentic activities in which to practice the concepts.

\section{Relevant Learning Activities}

I originally published music-theory OERs because I believed that traditional approaches to the subject do not include enough authentic activities. By explaining each concept in an open-access module, I hoped to make it available whenever it becomes relevant to a learner's music-making activities. However, the activities included in the OERs were similar to those in typical theory books. I assumed that learners or their teachers would supply the real-world activities. Such assumptions create barriers, particularly for independent learners struggling to make knowledgeexperience connections.

James relied on me to suggest guitar-based activities that would lead towards his goal, but was surprised by my first suggestion, to analyse the chord progression of a favourite piece and compose something using what he learned. He had expected a rote harmony exercise, but he took up the suggestion enthusiastically. James possessed the necessary skills and knowledges, but did not know how to use them together in this way. When he reported feeling overwhelmed, I proposed instead a variety of activities to focus his attention serially on the specific concepts and skills needed. His response suggested renewed confidence:

See, this is where having an experienced instructor makes a difference from looking at endless web pages. Now, I'm inspired to go on rather than give up or set it aside for longer than may be bealthy to my musical development (which I've done in the past). (James, contact 7) 
This scaffolded activity demonstrated to James how to make the progress he desired. Suggesting appropriate, authentic activities that are within the learner's zone of proximal development appeared to be a crucial step in helping participants create a knowledge-experience connection. Other participants, such as Jeff, Sonia, and Lee, also appeared to need suggestions for specific learning activities that were both doable and relevant to their goals.

\section{Focus of Attention}

The human brain is capable of coordinating many simultaneous automatic processes, but conscious attention is limited. One goal of education is to create new automatic processes, but this initially requires the learner to focus attention on the concepts and skills that need to be automaticized. This is why the use of familiar tools and actions in the inquiries was often the change-in-activity that led to progress. As James' inquiry illustrated, a crucial feature of good learning activities is that they are doable in part because they permit conscious attention to focus on only one new thing. Similarly, Sonia's fluency increased when we found ways to reduce the number of things that needed her conscious attention when she improvised.

In contrast, lack of a useful focus for Lee's attention appeared to be a barrier to progress that we failed to overcome. The numerous notes in a typical piano part tend to overwhelm the attention of someone trying to improvise or transpose them individually. Chord symbols, which represent specific groups of notes, are a notational shorthand used extensively in most jazz and popular genres for just this reason. They are an example of what makes theoretical concepts so powerful; they focus attention on one characteristic that various experiences have in common (Vygotsky, 1978). For example, Sonia, James, and Glen were capable musicians and music learners in part because they could use concepts such as $C 7$ chord to automatically categorize a variety of music reading, playing, and listening experiences. James' inquiry goals indicated a belief that better chord recognition would improve his composition skills, a belief supported by his progress. Like other jazz musicians, Sonia found that the more automatic her response to hearing, seeing, or playing a named chord, the smoother and more persuasive her improvisations became.

Lee reported that she had forgotten her chord theory; she could, for example, easily play the notes constituting a C7 chord and recognize whether they sounded appropriate in the music, but could not name the chord as such. Over the course of the study, her ability to interpret chord symbols improved, as did her ability to use them to create a piano part by extending an example. However, her ability to transfer the relevant knowledge to a new piece did not noticeably improve. It appeared that so much of her attention was focused on the chords that she could not focus on the skills she desired. The inability to categorize her experiences in terms of chord symbols may also have interfered with her ability to transfer what she learned to a new situation, because she could not focus during a learning activity on its useful, transferrable aspects.

\section{Goal-oriented feedback}

Feedback is also necessary for learning. Unlike the right/wrong feedback needed in rote exercises, feedback on authentic activities involves constructive criticism of the work in relation to the learning goal. Self-directed musicians often get sufficient feedback from self-assessment and audience response. However, as Lee's inquiry demonstrated, even experienced musicians may be able to hear the problems in their work yet not know how to solve them, leading to frustration rather than progress.

Glen volunteered self-assessment whenever he submitted his work. I did not limit my feedback to addressing concerns that he raised, but I did try to focus on possible solutions to problems he perceived. He sometimes tried following my suggestions, but as a knowledgeable and experienced 
musician, he often responded to my feedback by defending his creative choices. Near the end of the study, I pointed out that he had probably been capable of creating the compositions without my input and asked whether he thought the study had any effect. He responded by discussing the difficulties of staying motivated when his community of practice was not interested in his efforts:

I am much more productive in a collaborative environment. I don't get much of that from the guys I'm currently jammin' with. ... I see your ... involvement as somewhat of a catalyst. I think it has been significant. (Glen, contact 26)

It appears that the only thing Glen sought or received from the study was the additional motivation, as discussed above, and my "collaborative" feedback regarding his creative work.

Rote practice, requiring only right/wrong feedback, can be compatible with self-motivated inquiry when clearly tied in the learner's mind to the real-world goal. James and Lee, as well as other study participants, sought and completed such work. However, nearly all the participants were most interested in feedback on creative, open-ended activities. Sometimes this was, as with rote work, a matter of checking the correctness of a particular aspect of the creation:

I'm trying to do it by ear, and it's not easy. I would appreciate if you could review it before I start adding sevenths. (James)

[regarding a piano part she had created and then revised] I have made the amendments. ... Is this correct now please? (Lee)

Sometimes participants felt their work sounded wrong and were soliciting help in locating the problem:

I can't get the notes to sound right, especially the end. Any suggestions or help? (Jeff)

Would you please help me and see what's wrong ...? (Lee)

In some instances, however, participants were simply open to suggestions that might help improve either the current creation or subsequent works:

At this point, I'm not sure what to do with it. The ideas I have experimented with don't really seem to capture my attention. (Glen)

I have attempted as best I could and have added the percussion just for the fun of it. Please advise me more. (Jeff)

I'd appreciate any comments to belp me do better next time. (Sonia)

Participants sometimes reported that feedback led to a change that pleased them:

It does sound quite different! I've attached a new score. I've also played it on the guitar, and it sounds quite nice. (James)

Your first suggestion was very helpful. (Jeff)

Feedback also sometimes led to a shift in activity or focus of attention:

How do you know it is in Aeolian A minor? How do you recognise these kinds of things? (Jeff) 
Thank you for your very insightful comments. Your suggestions are very helpful. ... I will try your "no wrong note" approach. (Sonia)

\section{Conclusions}

As often happens in AR studies, the findings have changed my own perspective as a researcher. I remain committed to offering OERs that can be used independently, and I am working on new content that may help informal music learners create useful knowledge-experience connections for themselves. However, I do not want to ignore the implication that online materials are more useful when learners can move "seamlessly" between independence and guidance, as needed. Also, while some online learners may be most interested in quality content, others appear to prefer social learning activities (McAndrew et al., 2008). I now believe that a crucial avenue to pursue, to make my OERs more useful, is to tie them explicitly to various active supports that may be available through informal or formal learning situations, both online and locally. Many thriving online musical communities of practice already offer learners a variety of content, informal support, and formal help in the context of goal-oriented activities (e.g. Lysloff, 2003; Waldron, 2009). I have not yet found any that focus on the creative uses of theory, but involvement in this type of offering may be an important step for my future action research.

This small, qualitative study in the area of music cannot support general conclusions about selfmotivated learners who use OERs. Instead it illustrates some of the barriers they may encounter and the types of teacher assistance that help overcome these barriers. Like Jeff and James, selfmotivated learners may have backgrounds that are not well aligned with assumptions about "prerequisite" knowledge. Like Glen, their goals may not be well aligned with standard curriculum goals. Like Sonia and Lee, they may be busy adults who want or need to absorb new concepts and gain new skills at their own pace over extended periods of time. Given these situations, the study participants first tried to use OERs independently to learn within the contexts of the activities that motivated them. When this proved difficult, teacher involvement in their personal inquiries provided additional motivation, goal-oriented feedback, and authentic activities that focused their attention in ways that helped them connect formal knowledge to their real-world experiences.

The finding that self-motivated learners benefit from these aspects of inquiry guidance is not surprising; these issues are well-studied and recognized. What is new is the finding that it is these, rather other well-known issues, that appeared to be most crucial for learners who had both intrinsic motivation and access to a wealth of relevant materials. It is also important to stress that the benefits were provided through inquiry, with learners choosing goals as well as materials. Many approaches, like the MOOC that Sonia was enrolled in, use technology to reproduce traditional curricula rather than to offer a greater variety of goals, starting points, or pacing. The few MOOCs that are organized to support inquiry may overwhelm less-experienced students (Kop, Fournier, \& Mak, 2011). Nor do automated systems provide authentic-learning activities; as Lee (2008) has pointed out, they tend to close, rather than open up, learner choices. They cannot recommend materials and activities, and provide social motivation and feedback, for personalized learning paths. For example, there are automated systems that can check a music composition for correctness, but mere correctness is not sufficient to create a compelling, interesting piece:

In the book 'What Makes Music Work', I read a lot about melodic movement, and I tried to incorporate some of that. I find that it sounds like a sterile scale exercise, rather than a melody, and I'm not sure what to change to make it sound less 'theoretical'. (James, contact 19) 
A week ago I decided to dust off my theory book. I wasn't really getting anything significant out of it. ... just a bunch of uninspiring rules. ... The one thing I really took from theory is you can break all the rules if you can resolve your chords. (Glen, contact 18)

As Glen's inquiry demonstrated, what is motivational about feedback is the social connection to the human communities that value the activity.

In an information-rich environment, one of the most valuable uses of teaching time may be providing these supports within an inquiry-based pedagogy. In this study, learner motivation arose not from the processes of inquiry but from its connection to the learners' goals. The goals originally created the learners' desire for the formal knowledge and continued to motivate them throughout the process of discovering how to connect that knowledge to their real-world experiences. As James (contact 22) put it:

This has been immensely beneficial to me, and has fundamentally changed the way I listen to, and learn music. I will continue on my own, sporadic as it may be. ... I may stumble a lot more than if you were guiding me, but that's part of the learning as well.

\section{References}

1. Boitshwarelo, B. (2011). Proposing an integrated research framework for connectivism: Utilising theoretical synergies. International Review of Research in Open and Distance Learning, 12(3), 161-179.

2. Bresler, L. (1993). The social organization of achievement: A case study of a music theory class. The Curriculum Journal, 4(1), 37-58.

3. Brown, J. S., \& Adler, R. P. (2008). Minds on fire: Open education, the long tail, and learning 2.0. Educause Review, 43(1), 17-32. Retrieved from http://www.educause.edu

4. Brown, J. S., Collins, A., \& Duguid, P. (1989). Situated cognition and the culture of learning. Educational Researcher, 18(1), 32-42.

5. Burnard, P. (2007). Reframing creativity and technology: Promoting pedagogic change in music education. Journal of Music, Technology and Education, 1(1), 37-55. doi: https://doi.org/10.1386/jmte.1.1.37_1

6. Cape Town Open Education Declaration (2007). Read the Declaration. Retrieved from http:/ / www.capetowndeclaration.org/read-the-declaration

7. Carson, S. (2006). 2005 Program evaluation findings report. MIT OpenCourseWare. Retrieved from https://ocw.mit.edu/ans7870/global/05_Prog_Eval_Report_Final.pdf

8. Carson, S. (2009). 2009 Program Evaluation Findings Summary. MIT OpenCourseWare. Retrieved from http://ocw.mit.edu/ans7870/global/09_Eval_Summary.pdf

9. Crawford, R. (2014). A multidimensional/non-linear teaching and learning model: Teaching and learning music in an authentic and holistic context. Music Education Research, 16(1), 50-69. http://dx.doi.org/10.1080/14613808.2013.812627

10. Fletcher, G., Schaffhauser, D, \& Levin, D. (2012). Out of Print: Reimagining the K-12 Textbook in a Digital Age. Washington, DC: State Educational Technology Directors Association (SETDA).

11. Godin, S. (2012). Stop stealing dreams: (What is school for?). Retrieved from http://www.squidoo.com/seth\#module157797563 
12. Green, L. (2002). How popular musicians learn: A way ahead for music education. Farnham, England: Ashgate Publishing Limited.

13. Hargreaves, D. J., \& Marshall, N. A. (2003). Developing identities in music education. Music Education Research, 5(3), 263-274.

14. Harley, D. (2008). Why understanding the use and users of open education matters. In J. S. Brown, T. Iiyoshi, \& M. S. V. Kumar (Eds.), Opening up education: The collective advancement of education through open technology, open content, and open knowledge (pp. 197-211). Cambridge, MA: The MIT Press.

15. Heron, J., \& Reason, P. (2006). The practice of co-operative inquiry: Research 'with' rather than 'on' people. In P. Reason \& H. Bradbury (Eds.), Handbook of action research (Concise paperback ed.). Thousand Oaks, CA: Sage Publications.

16. Herr, K., \& Anderson, G. L. (2005). The action research dissertation: A guide for students and faculty. Thousand Oaks, CA: Sage Publications.

17. Knowles, M., \& Associates. (1984). Andragogy in Action: Applying Modern Principles of Adult Learning. San Francisco, CA: Jossey-Bass Inc.

18. Kop, R., Fournier, H., \& Mak, J. S. F. (2011). A pedagogy of abundance or a pedagogy to support human beings: Participant support on massive open online courses. International Review of Research in Open and Distance Learning, 12(7), 74-93

19. Lee, S. D. (2008). The gates are shut: Technical and cultural barriers to open education. In T. Iiyoshi \& M.S.V. Kumar (Eds.), Opening Up Education: The Collective Advancement of Education through Open Technology, Open Content, and Open Knowledge. Cambridge, MA: The MIT Press.

20. Leontiev, A. N. (1978). Activity, Consciousness, and Personality (M. J. Hall, Trans.). Retrieved from http://www.marxists.org/archive/leontev/works/1978/

21. Lilliestam, L. (1996). On Playing by Ear. Popular Music, 15(2), 195-216.

22. Lysloff, R. T. A. (2003). Musical community on the Internet: An on-line ethnography. Cultural Anthropology, 18(2), 233-263.

23. McAndrew, P., dos Santos, A. I., Lane, A., Godwin, S., Okada, A., Wilson, T., Connolly, T., Ferreira, G., Buckingham Shum, S., Bretts, J., \& Webb, R. (2008). OpenLearn: Research Report 2006-2008. Milton Keynes: OpenLearn, The Open University. Retrieved from http://www3.open.ac.uk/events/6/2009727_62936_o1.pdf

24. Nardi, B. A. (1996). Activity theory and human-computer-interaction. In Nardi (Ed.), Context and consciousness: Activity theory and human-computer interaction (pp. 7-16). Cambridge, MA: The MIT Press.

25. Nettl, B. (1985). The Western impact on world music: Change, adaptation, and survival. New York, NY: Schirmer Books.

26. Peters, J. M., Taylor, J. E., \& Doi, M. M. (2009). Self-directed learning and action research. International Journal of Self-Directed Learning, 6(2), 23-39.

27. Reason, P., \& Bradbury, H. (Eds.). (2006). Handbook of Action Research (concise paperback ed.) London: Sage Publications Ltd.

28. Rogoff, B. (1990). Apprenticeship in thinking: Cognitive development in social context. New York, NY: Oxford University Press.

29. Rosell-Aguilar, F. (2013). Podcasting for language learning through iTunes U: The learner's view. Language Learning \& Technology, 17(3), 74-93. 
30. Schmidt-Jones, C. (2012). An open education resource supports a diversity of inquiry-based learning. The International Review of Research in Open and Distance Learning, 13(1), 1-16.

31. Schmidt-Jones, C. (2016a). An online participatory action research inquiry into online inquiry-based music learning (Doctoral dissertation). Retrieved from https://www.ideals.illinois.edu/handle/2142/90449

32. Schmidt-Jones, C. (2016b). Barriers to self-motivated conceptual music learning: Activity theory as a framework for comparing dissimilar cases. Music Education Research, 16(2), doi: 10.1080/14613808.2016.1249362

33. Vygotsky, L. S. (1978). Mind in society: The development of higher psychological processes. (M. Cole, V. John-Steiner, S. Scribner, \& E. Souberman. Eds. A. R. Luria, M. Lopez-Morillas, M. Cole, \& J. Wertsch, Trans.) Cambridge, MA: Cambridge University Press.

34. Waldron, J. (2009). Exploring a virtual music 'community of practice': Informal music learning on the Internet. Journal of Music, Technology and Education, 2(2-3), 97-112. doi: 10.1386/jmte.2.2-3.97_1

35. Welch, G. F. (2007). Addressing the multifaceted nature of music education: An activity theory research perspective. Research Studies in Music Education, 28, 23-37.

36. Wells, G. (2001). Action, Talk, and Text: Learning and Teaching through Inquiry. New York, NY: Teachers College Press.

37. Wenger, E. (1998). Communities of practice: Learning, meaning and identity. Cambridge, England: Cambridge University Press.

38. Woody, R. H., \& Lehmann, A. C. (2010). Student Musicians' Ear-Playing Ability as a Function of Vernacular Music Experiences. Journal of Research in Music Education, 58(2), 101 115. doi: $10.1177 / 0022429410370785$ 